\title{
Risk Profile in Chronic Kidney Disease Stage 3: Older versus Younger Patients
}

\author{
Natasha J. Mclntyre ${ }^{a}$ Richard J. Fluck ${ }^{a}$ Christopher W. Mclntyre ${ }^{a, b}$ \\ Maarten W. Taal ${ }^{a}$ \\ a Department of Renal Medicine, Royal Derby Hospital, Derby, and ${ }^{b}$ Department of Vascular Medicine, \\ University of Nottingham, Nottingham, UK
}

\section{Key Words}

Cardiovascular disease $\cdot$ Chronic kidney disease $\cdot$

Epidemiology $\cdot$ Older patients $\cdot$ Risk factors

\begin{abstract}
Background: The prevalence of chronic kidney disease (CKD) increases with age, but its significance in older patients is uncertain and is regarded by some as part of 'normal aging'. Moreover, subjects $\geq 75$ years are often excluded from research studies. We therefore undertook a prospective study of patients with CKD stage 3 in primary care to compare the risk profile of older versus younger subjects. Methods: Subjects with an estimated glomerular filtration rate (eGFR) $59-30 \mathrm{ml} / \mathrm{min} / 1.73 \mathrm{~m}^{2}$ on two measurements were recruited from 32 primary care practices. Medical history and demographic data were obtained and participants underwent clinical assessment as well as urine and serum biochemistry tests. Results: 1,741 participants were recruited: mean age $72.9 \pm 9$ years; $60 \%$ female; $98 \%$ white; $17 \%$ diabetic. Mean eGFR was $52.5 \pm 10 \mathrm{ml} / \mathrm{min} / 1.73 \mathrm{~m}^{2}$ and $16.9 \%$ had albuminuria. Subjects $\geq 75$ years had a significantly lower eGFR than younger subjects and a higher risk profile characterised by greater albuminuria, more arterial stiffness and higher serum uric acid levels. Conclusion: Old-
\end{abstract}

\section{KARGER}

Fax +4161306 1234 E-Mail karger@karger.ch www.karger.com

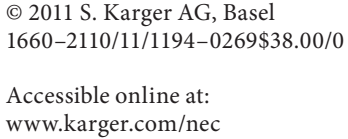

er subjects with CKD stage 3 evidenced a higher risk profile for CKD progression and cardiovascular events than younger patients. This implies that CKD is not a benign condition in all elderly patients, but further investigation is required to identify those at greatest risk who may benefit from intervention.

Copyright $\odot 2011$ S. Karger AG, Basel

\section{Introduction}

The prevalence of chronic kidney disease (CKD) increases with age [1-4] and is reported to be as high as $56.1 \%$ in those aged $\geq 75$ years [5]. Longitudinal studies suggest that at least some of this decline in glomerular filtration rate (GFR) may be due to 'normal aging'; therefore, the significance of CKD in the elderly remains uncertain. In particular, some have questioned whether a small reduction in GFR in the absence of albuminuria should be regarded as CKD [6]. Several studies have identified reduced GFR [7] and proteinuria as risk factors for increased cardiovascular as well as all-cause mortality [8]. In one study, the risk of developing end-stage kidney disease exceeded the risk of death only when GFR decreased to below $15 \mathrm{ml} / \mathrm{min} / 1.73 \mathrm{~m}^{2}$ among subjects $>65$
Dr. Maarten Taal

Department of Renal Medicine

Royal Derby Hospital

Uttoxeter Road, Derby DE22 3NE (UK)

Tel. +44 1332789 344, E-Mail maarten.taal@ derbyhospitals.nhs.uk 
Table 1. Inclusion and exclusion criteria

\section{Inclusion criteria}

Age 18 years or over

Meets KDOQI criteria for CKD stage 3 (GFR 30-59 ml/

$\mathrm{min} / 1.73 \mathrm{~m}^{2}$ on 2 occasions at least 3 months apart) using the

four-variable Modification of Renal Diet in Renal Disease

(MDRD) equation, prior to baseline study assessment

Able to give informed consent

Able to attend GP surgery for study assessments

Exclusion criteria

Terminally ill (expected survival $<1$ year)

Previous solid organ transplant

years [9]. It could therefore be argued that the detection of CKD in the elderly is useful mainly to identify those at increased cardiovascular risk, but whether or not this risk can be improved by medical interventions remains to be investigated. On the other hand, the detection of CKD in the elderly may be important because it is associated with complications such as anaemia, increased risk of acute kidney injury and has implications for drug dosing. Uncertainty about the significance of CKD in the elderly is particularly relevant to primary care physicians and is exacerbated by a relative lack of data because those $\geq 75$ years are often excluded from research studies [10-12].

Data from one community-based study of subjects $\geq 75$ years indicate that CKD is associated with significant co-morbidity in the elderly, including increased cardiovascular events (CVE), reduced physical and cognitive function, and a higher prevalence of potentially reversible factors such as anaemia. Furthermore, the strength of the association with co-morbid factors increased when estimated GFR (eGFR) fell below $45 \mathrm{ml} / \mathrm{min} / 1.73 \mathrm{~m}^{2}$ [5]. Long-term follow-up of these subjects confirmed that, similar to observations in younger subjects, reduced GFR (particularly GFR $<45 \mathrm{ml} / \mathrm{min} / 1.73 \mathrm{~m}^{2}$ ) was an independent risk factor for all-cause and cardiovascular mortality in older people. Despite results from other studies observing the contrary [7], dipstick proteinuria was associated with all-cause but not cardiovascular mortality [4]. This latter study was not, however, designed specifically to investigate CKD and was limited by reliance upon single creatinine measurements performed in one of 45 different laboratories without standardisation to an isotope dilution mass spectrometry (IDMS) method. Urinalysis was limited to dipstick testing. As only subjects $\geq 75$ years were studied, direct comparison with younger patients was not possible [5]. We therefore sought to inves- tigate the risk profile and co-morbidity of patients with CKD stage 3 aged $\geq 75$ years in greater detail and to compare them to subjects $<75$ years in a cohort recruited from primary care.

\section{Subjects and Methods}

\section{Subjects and Recruitment}

The Renal Risk in Derby (RRID) study was conducted from a single nephrology department, but subjects were recruited directly from 32 general practitioner (GP) surgeries. Eligible patients were invited to participate via a letter sent by their GP and telephoned the coordinating centre to schedule a study visit. Study visits were conducted at participating GP surgeries by the researchers. Inclusion and exclusion criteria are detailed in table 1.

\section{Data Collection}

Screening and baseline visits were combined due to the large proportion of elderly participants and the logistical challenges associated with conducting study visits in multiple primary care centres. Participants were sent a medical and dietary questionnaire as well as 3 urine specimen bottles, and were asked not to eat cooked meat for at least $12 \mathrm{~h}$ prior to the assessment [13]. Socio-economic status was assessed using the Indices of Multiple Deprivation (IMD) score (2007) derived from the postal code. This is a social deprivation score comprising a composite measure of seven domains. It is widely used in public health departments in the UK and has demonstrated a strong relationship to health in all geographical locations [14]. A higher IMD score indicates more social deprivation and a score of 21.67 (range: 2.66-80.62) represents average socio-economic status in England [15].

At the assessment, information on questionnaires was checked, anthropomorphic measurements taken (height, weight, BMI, waist-to-hip ratio) and urinalysis was performed. Blood specimens were taken and urine specimens were submitted for biochemical analysis. Blood pressure (BP) and pulse wave velocity (PWV) were also measured.

Diabetes was defined by having a previous clinical diagnosis in line with WHO criteria [16]. Previous CVE was defined as subject-reported myocardial infarction, stroke, transient ischaemic attack, revascularisation or amputation due to peripheral vascular disease, or aortic aneurysm. Central fat distribution was defined as a waist-to-hip ratio of $\geq 0.9$ for men or $\geq 0.8$ for women [17].

\section{Blood Pressure}

$\mathrm{BP}$ was measured after a minimum of 5 min rest in the sitting position, using a validated oscillometric device, recommended by the British Hypertension Society. The same device was used for all readings. BP was calculated as the mean of three readings that differed by $<10 \%$. Hypertension was defined by a systolic BP $\geq 140 \mathrm{~mm} \mathrm{Hg}$, diastolic BP $\geq 90 \mathrm{~mm} \mathrm{Hg}$, or current antihypertensive medication [18].

Pulse Wave Velocity

Carotid-to-femoral PWV was measured as a marker of arterial stiffness, a critical determinant of cardiovascular outcomes in CKD [19-21]. Measurements were performed using a Vicor- 
der $^{\text {TM }}$ device (Skidmore Medical Ltd., Bristol, UK) and were done in the semi-prone position (at approximately $30^{\circ}$ ) to prevent venous contamination of the arterial signal.

\section{Albuminuria}

Albuminuria was assessed by measuring the urine albuminto-creatinine ratio on three consecutive early morning urine specimens collected prior to the clinic visit and stored in a refrigerator. Microalbuminuria was defined as a mean urine albuminto-creatinine ratio of $>2.5 \mathrm{mg} / \mathrm{mmol}$ in males or $>3.5 \mathrm{mg} / \mathrm{mmol}$ in females [13].

\section{Estimation of GFR}

Biochemical assessments were performed by autoanalyser in a single laboratory. The creatinine assay was standardised against an IDMS method and the modified 4-variable MDRD equation was used to estimate GFR.

\section{Follow-Up and Endpoints}

Patients will be followed for up to 10 years. Clinical assessments will take place as described at baseline, 1 year and 5 years. The Medical Research Information Service (an arm of the NHS Information Centre) will be used to accurately track survival data and cause of death. The primary endpoint for assessing CKD progression will be doubling of serum creatinine, progression to CKD stage 5 or the need for renal replacement therapy. The primary endpoint for cardiovascular risk will be new CVE (myocardial infarction of any type, need for coronary revascularisation, TIA, fatal and non-fatal cerebrovascular accident, need for peripheral revascularization or amputation for peripheral vascular disease, death due primarily to peripheral vascular disease, or sudden cardiac death). Secondary endpoints will include changes in eGFR and urine albumin-to-creatinine ratio as well as allcause mortality.

The study was approved by the Nottingham Research Ethics Committee 1 and abides by the principles of the Declaration of Helsinki. All participants provided written consent. The study was included on the National Institute for Health Research Clinical Research Portfolio (Study ID: 6632) and was independently audited by QED Clinical Services in November 2009.

\section{Statistical Analysis}

Variables are reported as the mean and standard deviation (SD) if normally distributed or the median and inter-quartile range (IQR) if not. A t test was used to compare groups where variables were normally distributed and a Mann-Whitney test was used if not. SPSS version 15.0 was used for analysis and $p<$ 0.05 was considered statistically significant. With respect to longterm outcomes, the RRID study is adequately powered for time to event and repeated measures analysis. A sample size of 1,500 and exposure prevalence of 0.1 would give $80 \%$ power to detect a hazard ratio of approximately 1.8 .

\section{Results}

Overall, 22\% of the approximately 8,280 potential participants we invited agreed to be included in the study (range: $8-34 \%$ in different GP practices). A total of 1,822
Table 2. Baseline demographic data

\begin{tabular}{|c|c|c|c|}
\hline & $\begin{array}{l}\text { Total cohort } \\
(\mathrm{n}=1,741)\end{array}$ & $\begin{array}{l}\text { Subjects } \\
<75 \text { years } \\
(\mathrm{n}=917)\end{array}$ & $\begin{array}{l}\text { Subjects } \\
\geq 75 \text { years } \\
(\mathrm{n}=824)\end{array}$ \\
\hline Age, years & $72.9 \pm 9$ & $66.2 \pm 7$ & $80.3 \pm 4^{*}$ \\
\hline Female & $1,052(60)$ & $590(64)$ & $462(56)^{*}$ \\
\hline \multicolumn{4}{|l|}{ Ethnicity } \\
\hline White & $1,698(97.5)$ & $884(96.4)$ & $814(98.8)^{*}$ \\
\hline South Asian & $29(1.7)$ & $23(2.5)$ & $6(0.7)$ \\
\hline Afro-Caribbean & $5(0.3)$ & $2(0.2)$ & $3(0.4)$ \\
\hline Other & $9(0.6)$ & $8(0.8)$ & $1(0.1)$ \\
\hline \multicolumn{4}{|l|}{ No formal } \\
\hline qualifications & $953(54.7)$ & $436(47.5)$ & $517(62.7)^{*}$ \\
\hline IMD score & $17.7 \pm 11.3$ & $18.1 \pm 11.5$ & $17.4 \pm 11$ \\
\hline \multicolumn{4}{|l|}{ Smoking } \\
\hline Current & $81(4.7)$ & $63(6.9)$ & $18(2.2)^{*}$ \\
\hline Previous & $869(49.9)$ & $428(46.7)$ & $441(53.5)^{*}$ \\
\hline $\begin{array}{l}\text { Alcohol consumption } \\
\text { units/week }\end{array}$ & $5.6 \pm 9.6$ & $6.3 \pm 10.9$ & $4.9 \pm 8.0^{*}$ \\
\hline
\end{tabular}

Data are means $\pm \mathrm{SD}$, median (IQR) or $\mathrm{n}(\%) .{ }^{*} \mathrm{p} \leq 0.05$ vs. subjects $<75$ years.

subjects were enrolled between July 2008 and March 2010, but 81 were excluded because they did not meet the inclusion criteria despite being on a CKD register at their GP practice. Thus, a total of 1,741 participants were included in the study.

\section{Demographic Characteristics}

Data are summarised in table 2 . The mean age was $72.9 \pm 9$ years and $60 \%$ were female. The cohort was predominately white (98\%). Almost 55\% had no formal educational qualification. The mean IMD score indicates that most were of average socio-economic status. Less than $5 \%$ were current smokers, but half of the cohort had smoked in the past. There were significantly fewer female subjects amongst those $\geq 75$ years. A greater proportion of older subjects had no formal educational qualification, but current socio-economic status was not different to that of younger subjects. Fewer older subjects smoked tobacco and they consumed less alcohol than younger subjects, but a greater proportion had smoked in the past.

\section{Clinical Characteristics}

Data shown refer to the baseline assessment and are summarised in table 3. The mean eGFR was $52.5 \pm 10.4$ $\mathrm{ml} / \mathrm{min} / 1.73 \mathrm{~m}^{2}$ and the majority of subjects were therefore in CKD stage 3A (76\%). Despite previously meeting the eligibility criteria for CKD 3, 24\% had an eGFR of 
Table 3. Baseline clinical data

\begin{tabular}{|c|c|c|c|}
\hline & $\begin{array}{l}\text { Total cohort } \\
(\mathrm{n}=1741)\end{array}$ & $\begin{array}{l}\text { Subjects }<75 \text { years } \\
(\mathrm{n}=917 ; 53 \%)\end{array}$ & $\begin{array}{l}\text { Subjects } \geq 75 \text { years } \\
(\mathrm{n}=824 ; 47 \%)\end{array}$ \\
\hline $\mathrm{eGFR}, \mathrm{ml} / \mathrm{min} / 1.73 \mathrm{~m}^{2}$ & $52.5 \pm 10.4$ & $54.7 \pm 10.2$ & $50.1 \pm 10.1^{*}$ \\
\hline Albuminuria & 293 (16.9) & $143(18.2)$ & $150(15.6)$ \\
\hline Urinary ACR, mg/mmol & $0.33(0-1.5)$ & $0.23(0-1.17)$ & $0.53(0-1.87)^{*}$ \\
\hline Systolic BP, mm Hg & $134 \pm 18$ & $132 \pm 17$ & $137 \pm 19^{*}$ \\
\hline Diastolic BP, mm Hg & $73 \pm 11$ & $75 \pm 11$ & $71 \pm 11^{*}$ \\
\hline $\mathrm{BP}<140 / 90 \mathrm{~mm} \mathrm{Hg}$ & $1,117(64)$ & $641(70)$ & $476(58)^{*}$ \\
\hline Hypertension & $1,528(88)$ & $777(85)$ & $751(91)^{*}$ \\
\hline $\mathrm{PWV}, \mathrm{m} / \mathrm{s}$ & $9.9 \pm 2$ & $9.2 \pm 1.7$ & $10.6 \pm 2^{*}$ \\
\hline BMI & $29 \pm 5.1$ & $29.7 \pm 5.5$ & $28.3 \pm 4.6^{*}$ \\
\hline $\mathrm{BMI}>30$ & $650(37.3)$ & $393(42.9)$ & $257(31.2)^{*}$ \\
\hline Central fat distribution & $1,537(88.3)$ & $793(90.3)$ & $744(86.5)^{*}$ \\
\hline Haemoglobin, g/dl & $13.2 \pm 1.4$ & $13.4 \pm 1.4$ & $13.0 \pm 1.4^{*}$ \\
\hline Cholesterol, $\mathrm{mmol} / \mathrm{l}$ & $4.8 \pm 1.2$ & $4.9 \pm 1.2$ & $4.6 \pm 1.1^{*}$ \\
\hline $\mathrm{HDL}, \mathrm{mmol} / \mathrm{l}$ & $1.45 \pm 0.44$ & $1.44 \pm 0.44$ & $1.46 \pm 0.43$ \\
\hline Potassium, $\mathrm{mmol} / \mathrm{l}$ & $4.41 \pm 0.46$ & $4.47 \pm 0.46$ & $4.35 \pm 0.46^{*}$ \\
\hline Corrected calcium, mmol/l & $2.38 \pm 0.1$ & $2.38 \pm 0.1$ & $2.37 \pm 0.1$ \\
\hline Phosphate, $\mathrm{mmol} / \mathrm{l}$ & $1.11 \pm 0.18$ & $1.11 \pm 0.19$ & $1.10 \pm 0.17$ \\
\hline Glucose, $\mathrm{mmol} / \mathrm{l}$ & $6.3 \pm 2.5$ & $6.3 \pm 2.6$ & $6.3 \pm 2.3$ \\
\hline Bicarbonate, $\mathrm{mmol} / \mathrm{l}$ & $25.5 \pm 2.7$ & $25.5 \pm 2.6$ & $25.4 \pm 2.8$ \\
\hline Albumin, $\mathrm{mmol} / \mathrm{l}$ & $40.7 \pm 3.2$ & $41.1 \pm 3.3$ & $40.2 \pm 3.0^{*}$ \\
\hline Total protein, g/l & $74.3 \pm 4.9$ & $74.5 \pm 4.9$ & $74 \pm 4.8$ \\
\hline Uric acid, $\mu \mathrm{mol} / \mathrm{l}$ & $384 \pm 91$ & $378 \pm 91$ & $391 \pm 91^{*}$ \\
\hline Hyperuricaemia & $391(22.5)$ & $187(20.4)$ & $204(24.8)^{*}$ \\
\hline Previous CVE & $387(22)$ & $163(18)$ & $224(27)^{*}$ \\
\hline Diabetes mellitus & $294(17)$ & $155(17)$ & $139(17)$ \\
\hline Seen by nephrologist & $206(11.8)$ & $135(14.7)$ & $71(8.6)^{*}$ \\
\hline Renal biopsy & $40(2.3)$ & $29(3.2)$ & $11(1.3)^{*}$ \\
\hline RAASi use & $1,123(65)$ & $576(63)$ & $547(66)$ \\
\hline
\end{tabular}

Data are means $\pm \mathrm{SD}$, median $(\mathrm{IQR})$ or $\mathrm{n}(\%) .{ }^{*} \mathrm{p}<0.05$ vs. subjects $<75$ years. Albuminuria = Microalbuminuria or more severe; $\mathrm{ACR}=$ albumin-to-creatinine ratio; $\mathrm{HDL}=$ high-density lipoproteins; $\mathrm{RAASi}$ = renin-angiotensin-aldosterone system inhibitors.

Table 4. eGFR and urine albumin-to-creatinine ratio (uACR) in participant age groups of 5 years

\begin{tabular}{|c|c|c|c|c|c|c|}
\hline Age, years & $<40$ & $40-44.9$ & $45-49.9$ & $50-54.9$ & $55-59.9$ & $60-64.9$ \\
\hline \multicolumn{7}{|l|}{ Males } \\
\hline $\mathrm{n}$ & 1 & 1 & 5 & 9 & 21 & 57 \\
\hline uACR & - & - & $0.27(0-5.4)$ & $0.17(0.02-14)$ & $1.0(0.1-23)$ & $0.50(0.17-3.3)$ \\
\hline \multicolumn{7}{|l|}{ Females } \\
\hline $\mathrm{n}$ & 4 & 2 & 15 & 18 & 52 & 122 \\
\hline
\end{tabular}


$\geq 60 \mathrm{ml} / \mathrm{min} / 1.73 \mathrm{~m}^{2}$ at the first study visit. Only $17 \%$ of all subjects had microalbuminuria or more severe albuminuria, and the magnitude of albuminuria was generally low. Hypertension was present in $88 \%$ at entry, but BP was relatively well controlled with $64 \%$ of subjects having BP $<140 / 90 \mathrm{~mm} \mathrm{Hg}$. Mean PWV was increased compared to a weighted mean of $9.77 \mathrm{~m} / \mathrm{s}$ for a hypothetical population of healthy controls of similar age composition derived from published data [22]. Mean BMI was $29 \pm 5.1$ with $79.7 \%$ being either overweight or obese. Central fat distribution was highly prevalent, affecting $88 \%$. Twenty-two percent of subjects had a history of CVE and $17 \%$ had diabetes mellitus. Only $11.8 \%$ had previously been assessed by a nephrologist, but $65 \%$ were receiving therapy with a renin-angiotensin-aldosterone system inhibitor. Table 4 shows eGFR and urine albuminto-creatinine values in age groups of 5 years across the entire cohort.

Subjects $\geq 75$ years evidenced significantly lower eGFR than younger subjects and a significantly higher proportion were CKD stage 3B (eGFR: $30-44 \mathrm{ml} / \mathrm{min}$ / $1.73 \mathrm{~m}^{2}$ ). The prevalence of albuminuria was similar, but the magnitude of albuminuria was significantly higher amongst those $\geq 75$ years. Systolic BP was higher and diastolic pressure lower in older subjects. PWV was significantly higher in those $\geq 75$ years. Older subjects had a lower mean BMI and prevalence of central fat distribution. Haemoglobin and serum albumin were slightly, but significantly, lower and serum uric acid levels were significantly higher than in younger subjects. A greater proportion of older subjects had hyperuricaemia. Those $\geq 75$ years evidenced a higher prevalence of previous CVE. Fewer older subjects had previously been assessed by a nephrologist or had a renal biopsy, but there was no difference in the proportion receiving renin-angiotensinaldosterone system inhibitor therapy.

Among subjects $\geq 75$ years, comparison between CKD stages $3 \mathrm{~A}$ and $3 \mathrm{~B}$ revealed that those with $\mathrm{CKD} 3 \mathrm{~B}$ evidenced a higher prevalence and magnitude of albuminuria as well as more hypertension. CKD stage $3 \mathrm{~B}$ was also associated with a higher prevalence of anaemia, higher serum uric acid levels and lower serum bicarbonate (table 5).

\section{Discussion}

On the basis of age, GFR and proteinuria, the RRID study cohort is broadly representative of patients with CKD followed up in primary care in the UK [23]. In particular, our subjects who were $\geq 75$ years were similar with respect to age and gender ratio to those included in the Medical Research Council (MRC) Trial of Assessment and Management of Older People in the Community $[4,5]$. Our data confirm observations from the MRC trial that subjects $\geq 75$ years evidenced a high-risk profile with respect to risk factors for CKD progression and CVE, and additionally show that this risk profile is higher than that observed in younger subjects. As regards CKD progression, older subjects had a lower mean eGFR, higher prevalence of CKD stage $3 \mathrm{~B}$, greater magnitude of albuminuria and higher systolic BP. Reduced GFR and

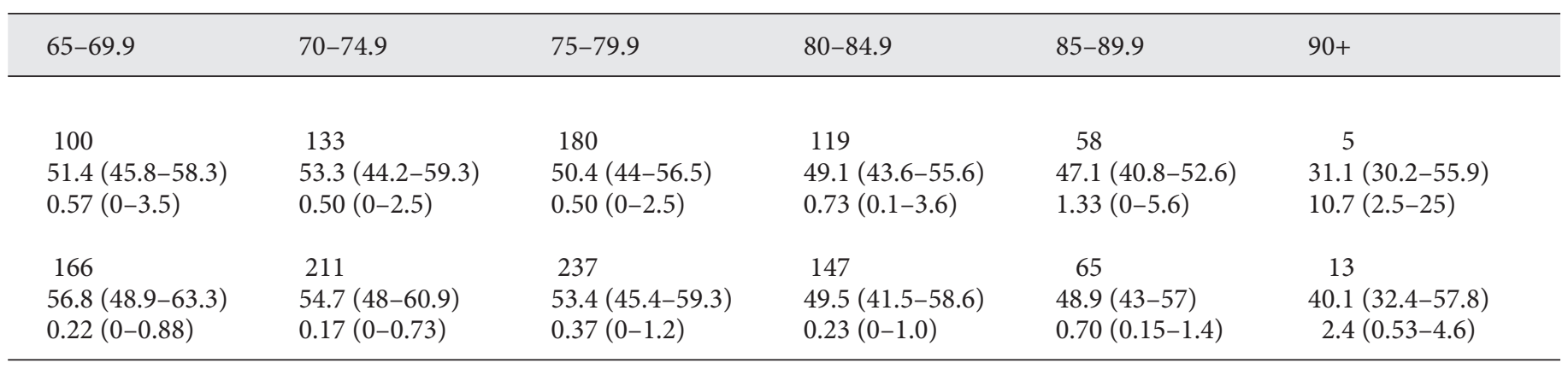


Table 5. Comparison between CKD stages $3 \mathrm{~A}$ and $3 \mathrm{~B}$ among subjects aged $\geq 75$ years

\begin{tabular}{|c|c|c|c|}
\hline & $\begin{array}{l}\text { CKD 3A } \\
n=567(69)\end{array}$ & $\begin{array}{l}\text { CKD 3B } \\
\mathrm{n}=257(31)\end{array}$ & $\begin{array}{l}\mathrm{p} \\
\text { value }\end{array}$ \\
\hline Age, years & $79.9 \pm 3.9$ & $81.1 \pm 4.1$ & \\
\hline Female & $326(57.5)$ & $136(53)$ & NS \\
\hline White ethnicity & $561(98.9)$ & $253(98.4)$ & NS \\
\hline \multicolumn{4}{|l|}{ Smoking } \\
\hline Current & $10(1.8)$ & $8(3.1)$ & NS \\
\hline Previous & $295(52)$ & $146(57)$ & NS \\
\hline $\mathrm{eGFR}, \mathrm{ml} / \mathrm{min} / 1.73 \mathrm{~m}^{2}$ & $55.4 \pm 6.7$ & $38.3 \pm 5.1$ & $<0.0001$ \\
\hline Albuminuria & $80(14.1)$ & $70(27.2)$ & $<0.0001$ \\
\hline Urinary ACR, $\mathrm{mg} / \mathrm{mmol}$ & $0.37(0-1.3)$ & $1.0(0.13-3.3)$ & $<0.0001$ \\
\hline Systolic BP, mm Hg & $137 \pm 19$ & $137 \pm 20$ & NS \\
\hline Diastolic BP, mm Hg & $71 \pm 11$ & $69 \pm 11$ & 0.007 \\
\hline Hypertension & $505(89)$ & $246(96)$ & 0.002 \\
\hline $\mathrm{PWV}, \mathrm{m} / \mathrm{s}$ & $10.6 \pm 2$ & $10.7 \pm 2.1$ & NS \\
\hline BMI & $28.3 \pm 4.5$ & $28.1 \pm 4.7$ & NS \\
\hline Haemoglobin, g/dl & $13.2 \pm 1.3$ & $12.6 \pm 1.5$ & 0.001 \\
\hline Anaemia & $130(22.9)$ & $106(41.2)$ & $<0.0001$ \\
\hline Cholesterol, mmol/l & $4.7 \pm 1.2$ & $4.6 \pm 1.0$ & NS \\
\hline Albumin, $\mathrm{mmol} / \mathrm{l}$ & $40.3 \pm 3.0$ & $39.9 \pm 3.1$ & NS \\
\hline Uric acid, $\mu \mathrm{mol} / \mathrm{l}$ & $371 \pm 82$ & $437 \pm 93$ & $<0.0001$ \\
\hline Hyperuriceamia & $96(16.9)$ & $108(42)$ & $<0.0001$ \\
\hline Previous CVE & $147(25.9)$ & $77(30)$ & NS \\
\hline Diabetes mellitus & $95(16.8)$ & $44(17.1)$ & NS \\
\hline Seen by nephrologist & $19(3.4)$ & $52(20.2)$ & $<0.0001$ \\
\hline RAASi use & $357(63)$ & $190(73.9)$ & 0.002 \\
\hline
\end{tabular}

Data are means $\pm \mathrm{SD}$, median (IQR) or $\mathrm{n}(\%)$. Albuminuria $=$ Microalbuminuria or more severe; $\mathrm{ACR}=$ albumin-to-creatinine ratio; $\mathrm{HDL}=$ high-density lipoproteins; $\mathrm{RAASi}$ = renin-angiotensin-aldosterone system inhibitors.

the presence of albuminuria have also been identified as cardiovascular risk factors [8]. In addition, those $\geq 75$ years had higher systolic and lower diastolic BP as well as higher PWV, consistent with increased arterial stiffness. Increased arterial stiffness is emerging as a major risk factor for CVE $[24,25]$ and has been identified as an independent risk factor for cardiovascular death in the general population [26] as well as in subjects with CKD [20, $27,28]$. Uric acid levels, identified in previous studies as an independent cardiovascular risk marker in subjects with [29] and without CKD [30-32], were also higher in the elderly. Thus, greater albuminuria, increased arterial stiffness and elevated uric acid levels are some of the factors that may account for the higher cardiovascular risk observed in older subjects with CKD.

Among older subjects, comparison of CKD stages $3 \mathrm{~A}$ and $3 \mathrm{~B}$ confirmed that the latter group represents a high- er risk group and evidenced a substantially higher prevalence of anaemia, though it should be conceded that a greater proportion of those with CKD stage $3 \mathrm{~B}$ were receiving treatment with a renin-angiotensin-aldosterone system inhibitor that may have contributed to the development of anaemia. These observations are consistent with data from the MRC trial that reported higher cardiovascular and all-cause mortality in subjects with GFR $<45 \mathrm{ml} / \mathrm{min} / 1.73 \mathrm{~m}^{2}$ [4]. Thus, one strategy for dealing with the large proportion of older people with CKD stage 3 may be to focus on the higher risk group represented by stage $3 \mathrm{~B}$ (31\% in our cohort).

It has been argued that in the elderly, a small reduction in GFR in the absence of albuminuria should not be regarded as CKD, but as a manifestation of 'normal aging' [6]. As shown in table 4, GFR values in the RRID cohort were substantially lower than those reported in a population-based study of healthy adults in Northern Europe [33], implying that our participants evidenced a greater reduction in GFR than could be accounted for by aging. Nevertheless, since a large proportion of the participants were within CKD stage $3 \mathrm{~A}$ and lacked albuminuria, this study affords the opportunity to investigate outcomes and the associated risks in this controversial subgroup.

Our data show that although CKD stage 3 may be highly prevalent among those $\geq 75$ years, it is not a benign phenomenon and is associated with a higher risk profile for CKD progression and CVE than in younger patients. Furthermore, some of these risk factors including albuminuria, arterial stiffness and uric acid levels are potentially modifiable, though the benefits of such interventions remain to be tested in randomised trials. Despite this higher risk profile, fewer older patients had been referred to a nephrologist or had undergone a renal biopsy. This is likely because of perceptions, confirmed by longitudinal studies [4, 9], that the risk of death substantially outweighs the risk of CKD progression in the elderly. Despite this, it is also true that the greatest increase in patients receiving dialysis in the US [34] and UK [35] is among the elderly. Furthermore, progression of CKD without the need for renal replacement therapy may nevertheless be associated with an increase in complications such as anaemia, increased risk of acute kidney injury and a need for adjustment of medication doses. The planned long-term follow-up of this cohort will seek to identify risk factors that identify those at greatest risk who may benefit from more intensive intervention and the data will inform the design of future studies to test the efficacy of interventions to reduce risk in these patients. 
Strengths of this study include confirmation of CKD stage 3 by two eGFR values (often lacking in epidemiological studies), serum creatinine measurements performed after a 12-hour meat fast and samples assayed in a single laboratory using an assay standardised to an IDMS method, urine chemistry repeated on three consecutive early morning specimens to minimise the effect of daily variation in low levels of albuminuria, and collection of survival data via a national data centre. We have therefore established a robust baseline dataset that will allow detailed analysis of the predictive value of potential risk factors among older and younger subjects when outcome data become available.

Several limitations of this study need to be acknowledged. Despite rigorous application of the entry criteria, some subjects had an eGFR $\geq 60 \mathrm{ml} / \mathrm{min} / 1.73 \mathrm{~m}^{2}$ at their first clinical visit. Follow-up will yield important data on the natural history and associated risks of this subgroup. For ethical reasons we were obliged to rely on eligible patients volunteering to participate and this strategy may have introduced an element of bias, since those more concerned about their health would be more likely to participate. As discussed, however, the RRID cohort is broadly representative of patients followed up in primary care with CKD stage 3, though it may not be representative of all such populations. The cohort includes only a minority of subjects of African or Asian origin as the population in Derbyshire is predominantly Caucasian. Several studies have reported a high prevalence of CKD in African and Asian populations associated with a higher risk of CKD progression and our observations may therefore not be directly applicable to these ethnic groups.

\section{Conclusion}

Older subjects with CKD stage 3 evidence a higher risk profile for CKD progression and CVE than younger patients. Long-term follow-up will allow assessment of the value of a wide range of risk factors to predict outcomes in this group and to identify high-risk groups for possible intervention. Further studies are required to investigate the efficacy of interventions to reduce risk in older subjects.

\section{Acknowledgements}

This study was supported by a fellowship grant from Kidney Research UK and the British Renal Society, as well as an unrestricted educational grant from Roche Products Plc.
Thanks go to the collaborating GP practices and their staff: Dr. Shand and Partners, Osmaston Road Medical Centre, Derby; Dr. Gates and Partners, Chapel St. Medical Centre, Derby; Dr. Hamilton and Partners, The Old Station Surgery, Ilkeston; Dr. Kirtley and Partners, The Clifton Road Surgery, Ashbourne; Ascot Road Medical Centre, Derby; Dr. Gould and Partners, The Golden Brook Practice, Long Eaton; Meadowfields Practice, Derby; Dr. Orchard and Partners, The Limes Medical Centre, Alfreton; Blackwell Medical Centre, Alfreton; The Village Surgery, Pinxton; Dr. Doris and Partners, The Vicarage Road Medical Centre, Derby; Dr. Harris and Partners, Alvaston Medical Centre, Derby; Dr. Black and Partners, Melbourne Health Care Centre, Melbourne, Derby; Dr. Vickers and Partners, Wellbrook Medical Centre, Hilton, Derby; Dr. Hanna and Partners, Cavendish Way Surgery, Derby; Dr. Starey and Partners, Gresleydale Healthcare Centre, Swadlincote, Derbyshire; Dr. Jones and Partners, Ivy Grove Surgery, Ripley, Derbyshire; Dr. Chadwick and Partners, Ashenfell Surgery, Baslow, Derbyshire; Dr. Lockhart and Partners, Bakewell Medical Centre, Bakewell, Derbyshire; Dr. Bakshi, Jaybee Medical Centre, Derby; Dr. Zammit-Maempel, The Hena Medical Centre, Derby; Normanton Medical Centre, Derby; Dr. Iqbal, Clarence Road Surgery, Derby; Dr. Skidmore and Partners, Parkside Surgery, Alfreton; Dr. Thomson and Partners, The Park Medical Practice, Chaddesden, Derby; Dr. Edyvean and Partners, Derwent Medical Centre, Derby; Dr. O’Reilly and Partners, The Brook Medical Centre, Derby; Dr. Cotton and Partners, The Village Community Medical Centre, Derby; Dr. Donaldson and Partners, Whitemoor Medical Centre, Belper, Derbyshire; Dr. Ahmed and Partners, The Park Surgery, Heanor, Derbyshire; Dr. Taylor and Partners, Ripley Medical Centre, Ripley, Derbyshire; Dr. Harrison and Partners, Woodville Surgery, Swadlincote, Derbyshire.

In addition, we gratefully acknowledge the invaluable assistance of Mrs. Diane Taal, Ms. Rani Uppal, Mrs. Rebecca Packington, Mrs. Maureen Franklin, Mrs. Sue Hodkinson, Mr. Richard Turck and Mrs. Paula Welch. We also thank all the participants for their time and commitment.

\section{Disclosure Statement}

The results presented in this paper have not been published previously in whole or in part, except in abstract form.

References

1 Chadban SJ, Briganti EM, Kerr PG, et al: Prevalence of kidney damage in Australian adults: the AusDiab Kidney Study. J Am Soc Nephrol 2003;14:S131-S138.

2 Hallan SI, Dahl K, Oien CM, et al: Screening strategies for chronic kidney disease in the general population: follow-up of cross sectional health survey. BMJ 2006;333:1047.

-3 Clase CM, Garg AX, Kiberd BA: Prevalence of low glomerular filtration rate in nondiabetic Americans: Third National Health and Nutrition Examination Survey (NHANES III). J Am Soc Nephrol 2002;13:1338-1349. 
4 Roderick PJ, Atkins RJ, Smeeth L, et al: CKD and mortality risk in older people: a community-based population study in the United Kingdom. Am J Kidney Dis 2009;53:950960.

5 Roderick PJ, Atkins RJ, Smeeth L, et al: Detecting chronic kidney disease in older people: what are the implications? Age Ageing 2008;37:179-186.

6 Glassock RJ, Winearls C: An epidemic of chronic kidney disease: fact or fiction? Nephrol Dial Transplant 2008;23:1117-1121.

7 Go AS, Chertow GM, Fan D, et al: Chronic kidney disease and the risks of death, cardiovascular events, and hospitalization. New Engl J Med 2004;351:1296-1305.

$\checkmark 8$ CKD Consortium: Association of estimated glomerular filtration rate and albuminuria with all-cause mortality in general population cohorts: a collaborative meta-analysis. Lancet 2010;375:2073-2081.

-9 O'Hare AM, Choi AI, Bertenthal D, et al: Age affects outcomes in chronic kidney disease. J Am Soc Nephrol 2007;18:2758-2765.

$\checkmark 10$ Levey AS, Adler S, Greene T, et al: Effects of dietary protein restriction on the progression of moderate renal disease in the Modification of Diet in Renal Disease Study. J Am Soc Nephrol 1996;7:2616-2626.

-11 Lash JP, Go AS, Appel LJ, et al: Chronic Renal Insufficiency Cohort (CRIC) Study: baseline characteristics and associations with kidney function. Clin J Am Soc Nephrol 2009; 4: 1302-1311.

-12 Brenner BM, Cooper ME, de Zeeuw D, et al: Effects of losartan on renal and cardiovascular outcomes in patients with type 2 diabetes and nephropathy. New Engl J Med 2001;345: 861-869.

13 The National Institute for Health and Clincal Excellence: National clinical guideline for early identification and management in adults in primary and secondary care. www. nice.org.uk/nicemedia/pdf/CG073NICEGuideline.pdf. 2008.
14 Jordan H, Roderick P, Martin D: The Index of Multiple Deprivation 2000 and accessibility effects on health. J Epidemiol Community Health 2004;58:250-257.

15 The Office of National Statistics: http:// www.neighbourhood.statistics.gov.uk/dissem in at ion/Info.do? page =news / newsitems/7-december-2007-indices-ofdeprivation-2007.htm. 2010.

16 The World Health Organisation and the International Diabetes Federation: Definition and diagnosis of diabetes mellitus and intermediate glycaemia. Geneva, WHO Press, 2006.

17 Pinto-Sietsma SJ, Navis G, Janssen WM, et al: A central body fat distribution is related to renal function impairment, even in lean subjects. Am J Kidney Dis 2003;41:733-741.

18 Chobanian AV, Bakris GL, Black HR, et al: The Seventh Report of the Joint National Committee on Prevention, Detection, Evaluation, and Treatment of High Blood Pressure: the JNC 7 report. JAMA 2003;289: 2560-2572.

19

Blacher J, Guerin AP, Pannier B, et al: Impact of aortic stiffness on survival in end-stage renal disease. Circulation 1999;99:2434-2439.

20 Blacher J, Safar ME, Guerin AP, et al: Aortic pulse wave velocity index and mortality in end-stage renal disease. Kidney Int 2003;63: 1852-1860.

-21 Safar ME, Blacher J, Pannier B, et al: Central pulse pressure and mortality in end-stage renal disease. Hypertension 2002;39:735-738.

$\checkmark 22$ Khoshdel AR, Thakkinstian A, Carney SL, Attia J: Estimation of an age-specific reference interval for pulse wave velocity: a metaanalysis. J Hypertens 2006;24:1231-1237.

$\checkmark 23$ de Lusignan S, Tomson C, Harris K, et al: Creatinine fluctuation has a greater effect than the formula to estimate glomerular filtration rate on the prevalence of chronic kidney disease. Nephron Clin Pract 2011; 117:c213-c224.

24 Mattace-Raso FU, van der Cammen TJ, Hofman A, et al: Arterial stiffness and risk of coronary heart disease and stroke: the Rotterdam Study. Circulation 2006;113:657663.
25 Mitchell GF, Hwang SJ, Vasan RS, et al: Arterial stiffness and cardiovascular events: the Framingham Heart Study. Circulation 2010; 121:505-511.

26 Vlachopoulos C, Aznaouridis K, Stefanadis C: Prediction of cardiovascular events and all-cause mortality with arterial stiffness: a systematic review and meta-analysis. J Am Coll Cardiol 2010;55:1318-1327.

27 Chue CD, Townend JN, Steeds RP, Ferro CJ: Arterial stiffness in chronic kidney disease: causes and consequences. Heart 2010;96: 817-823.

28 Blacher J, Guerin AP, Pannier B, et al: Arterial calcifications, arterial stiffness, and cardiovascular risk in end-stage renal disease. Hypertension 2001;38:938-942.

29 Madero M, Sarnak MJ, Wang X, et al: Uric acid and long-term outcomes in CKD. Am J Kidney Dis 2009;53:796-803.

30 Short RA, Johnson RJ, Tuttle KR: Uric acid, microalbuminuria and cardiovascular events in high-risk patients. Am J Nephrol 2005;25:36-44.

31 Gagliardi AC, Miname MH, Santos RD: Uric acid: a marker of increased cardiovascular risk. Atherosclerosis 2009;202:11-17.

32 Okura T, Higaki J, Kurata M, et al: Elevated serum uric acid is an independent predictor for cardiovascular events in patients with severe coronary artery stenosis: subanalysis of the Japanese Coronary Artery Disease (JCAD) Study. Circ J 2009;73:885-891.

33 Wetzels JF, Kiemeney LA, Swinkels DW, et al: Age- and gender-specific reference values of estimated GFR in Caucasians: the Nijmegen Biomedical Study. Kidney Int 2007;72: 632-637.

34 United States Renal Data System: The 2010 USRDS Annual Data Report (ADR) Atlas of ESRD. www.usrds.org/atlas.htm. 2010.

35 Ansell D, Feehally, J, Fogarty D, Inward C, Tomson C, Warwick G, Williams AJ (eds): UK Renal Registry 12th Annual Report. 2009. Nephron Clin Pract 2010;115(suppl 1). 